\title{
Effectiveness of Education of Affectional Contact Skills on Lonely Sense and Social Emotional Learning of Children above 10 Years of Mothers (Nurses) Night Shift of Saveh City Hospitals
}

\author{
Mozhgan Haj Alimohammadi ${ }^{1}$, Fatemeh Shateriyan Assistant $^{2}$ \& Azadeh Farghadani $^{2}$ \\ ${ }^{1}$ Masters, Azad University of Saveh, Iran \\ ${ }^{2}$ Assistant Professor, Azad University of Saveh, Iran \\ Correspondence: Azadeh Farghadani, Azad University of Saveh, Iran. E-mail: editor.hna@gmail.com
}

Received: April 25, 2016

Accepted: June 12, 2016

Online Published: April 23, 2017

doi:10.5539/mas.v11n6p1

URL: https://doi.org/10.5539/mas.v11n6p1

\begin{abstract}
The aim of this research was determination of effectiveness amount of education of affectional contact skills on lonely sense and social emotional learning of children above 10 years of mothers (nurses) night shift of Saveh city hospitals. The way of this research is an experiment with plan of pretest and posttest with experiment and control group. The sample of research includes 40 practitioner nurses women in night shifts in hospital and 40 childs above 10 years. In this research, recommendation of affectional contact skills for learning mothers was used. For collecting information, the scale of lonely sense of Asher children and scale of social- emotional learning on children as pretest and posttest was done. In this research, the software (Spss) was used for analyzing data. The findings suggest that education of affectional contact skills on lonely sense and also on social-emotional learning of children above 10 years of mothers (nurses) night shift of Saveh city hospitals is useful.
\end{abstract}

Keywords: lonely sense, affectional contact skills, social-emotional learning

\section{Introduction}

The family is one of the most important factors effective on comprehensive grow of child. In family, the child give the first view of around world and sense of exist is come out. One of the consequences of applying educations of affectional contact skills is access to skills that basically effect on educational, business and social function of persons and have a very fundamental role in education progress and success in life. Therefore education of affectional contact skills can improve educational present achievements. Neglect to importance and necessity of education of such skills not only thread future, but always this worry exists for mothers that are in night shift, that their children due to this sense of lonely injured and in comparison with other children, socially and emotionally cannot learn necessary points for presence in society and show emotions (brendek and hamidi, 2007).

Alavi (2004, according to Sadeghi, 2011) says: the family is an order of complex personal interactions that as conditions, roles, customs in form of one social order has mutual contact with bigger society, its norms and values have imminent effect on behavior and personality of person.

The mother responsibility in educative and educational problems, considered as very important responsibility, because mother is not only responsible of own completeness, but is responsible of happiness or adversity of future generation. Today, the developments such as mothers' occupation and being away from intimate environment of home, changes the stability of family relations, has entrusted the way of upbringing of children to environment out of family. One of the important changes in today life is increase the number of practitioner mothers out of home. Clark and Stewart (1993) believe that the most important cause of this ascending progress is commercial and financial problems.

Milgeram (1990) considers family condition as the basic factors in realizing inherent abilities of human. He refers to researches that have showed that behavior in attitude of parents and quantity and quality of their interests and way of connect with children in their grows and abilities is completely effective.

One of our existence necessities is need to sociability and association with others. The source of this necessity is 
our social life.

Loneliness is unpleasant mood that deviate from difference in relations among the person who wants it and relations that others are in real conditions. This sense is important because emotional modes of persons interdependent with social poverty, behavior and health in mature persons and teenagers and children (3Kvaltr, Brown, Rothenberg, the holst Harris, et al 2013).

The affection in education is very important. The more persons belive that emotional view is important for life (Salovey, Mayer and Karsv 2002) because arises attention and make learning and reinforcement of memory. There is no doubt that the way of cohesion of behaviors and emotions and recognitions in first decade of growing has important function in emotional and mental act of person in through life.

Social emotional learning is defined as progress of acquisition basic skills needed for recognition and management of emotions, making worry sense and care to others, making responsible decisions, making positive relations and efficient opposition with challengeable conditions (university association of social emotional learning 2008).

Educational programs in field of affectional connect have codified on base of theories such as social learning (Bendora, 1977), cognitive grow pattern (Hakenz and weez, 1985), ecology theory (bern van broner, 1977), behavior difficulties theory (jessy and jessy, 1977) and fichbern's logical act theory. Each of these theories informs foundation of a part of each educational program in field of emotional and social skills. These programs effects on social and affectional skills such as consciousness, group work, compassion for self and others (Hawkins et al, 2001). Through these programs, the persons learn to recognize own affections and to apply own cognition and interpersonal skills in a suitable way (paghalejamali et al, 2013, 4-10)

Therefore, the need to adding programs for learning affectional connect skills in various periods of education for mothers that have night shift, is obvious, but do you can write a program that applying it leads to improve emotional connect skills and reduce of lonely sense and decrease of social affectional learning of children above 10 years of mothers in night shift?

\section{Way of Research}

Way of research is semi-experiment of kind (pretest and posttest plot with control group). In this research, education of affectional connect skills considered as independent variable and loneliness sense and social-affectional dependent variable. The children above 10 years with their mothers that have night shift and are practitioner in Saveh city hospitals in 2014 are considered as control variables of this research. Statistical population of this research is included as all mothers that have night shift in Saveh city hospitals that have children above 10 years that number of them is 40 persons. In this research, for sampling of mothers due to list of all of them and by way of census, all of population persons are chosen as statistical case. So they substituted as accidentally in experiment groups (20 persons) and control (20 persons). First it examined on two groups, so experimental intervention (education of affectional connect skills) on experiment group is done at 8 meetings and after end of educational meetings, posttest on two group has done again, for analyzing data, descriptive and inferential statistics was used. In descriptive statistics, frequency, percent, mean, standard variation, and in inferential statistics, data is examined: because of that research plot, pretest plot, pertest-posttest do with control group, for adjustment effect of scores of pretest on posttest and determination of effectiveness of intervention and examination of hypotheses of research, analyzing multivariable covariance (MANCOVA) was used (delavar, 2010). While analyzing data was done by SPSS software.

\section{Measurement tools}

\subsection{Affectional Connect Skills}

The aim of educations of affectional connect skills is a score that exams that over 8 meetings and 9 hours from educations that researcher himself has designed, supervisors and consultant confirm it and they access content story of it to learned exercises review and exercise it again. It is necessary to notice that before start of classes, children are pre tested and after 2 month educating mothers, they post tested again. The considered questions being consistent to stated problems by mothers.

Table 1.

\begin{tabular}{ll}
\hline Meetings & Educational content of affectional connect skill \\
\hline First meeting & $\begin{array}{l}\text { Applying pretest, introduction and introducing group members to each other. } \\
\text { Introducing program of education of affectional connect skill }\end{array}$ \\
\hline
\end{tabular}




\begin{tabular}{|c|c|}
\hline Second meeting & Education of respect to child, and what work you must done if you upset from child \\
\hline Third meeting & Education of kissing child and interaction against bad social behaviors \\
\hline Forth meeting & $\begin{array}{l}\text { Education of hugging child interaction against watching TV and computer games } \\
\text { too much }\end{array}$ \\
\hline Fifth meeting & Education of advising with children and preparing child for being alone in home \\
\hline Sixth meeting & $\begin{array}{l}\text { Education of using verbal enforcements such as applause and ... and nonverbal } \\
\text { such as present and education of acting against discussion and children debate }\end{array}$ \\
\hline Seventh meeting & Reaction against protests of children and concluding declaration of end of meetings \\
\hline Eighth meeting & Conclusion and ending and post test \\
\hline
\end{tabular}

\subsection{Lonliness Scale of Ashr Children}

This scale evaluates child's sense of loneliness of social unpleasant. It includes 24 matters/ 8 matters of it (2-4-5-11-13-15-19-23) is related to entertainment and children interests and no number applied to it, and it came for it that child in doing exam feels easily sense and more pleasant and freedom; and 16 number applied to it and its range is between 16 and 80 . According to ranking scale of Likert it is graded and each phase between 1 and 5 is graded. Ending coefficient of this exam by using split off was $83 \%$ and by using sperman-brown method, ending coefficient was $91 \%$, and also by using gatman split off method $\mathrm{r}=91$ (schrohaimel and Renshaw, 1984). Ending coefficient is achieved by majdian (2008) by open exam by interval 25 days on 41 students of one secondary girl school, $\mathrm{r}=49 \%$.

In calculations related to payayee (hosseinchari, 2002) it clarified that debated scalr have a suitable internal stability.Alpha Cronbach coefficient is $81 \%$ and its internal homology due to correlation is $66 \%$ between to half exams and by using split-half method is in accepted level that this amount, after correcting sperman-brown method for calculating ending coefficient of whole scalr is $79 \%$. Ending coefficient canman is $79 \%$ that is in accepted level and suggest suitable reliability.

\subsection{Social-Affectional Learning Scale}

Social-affectional learning scale is a questionnaire self-reports that includes 20 items. It is made for measuring Social-affectional learning that as Likert five degrees from very low to very high, is responded. Social-affectional learning is a plan for inter to three aspect of Social-affectional learning: 1 - it includes organization of task of responsible decision 2 - peers relations includes social knowledge and relations skills and 3 - self-regulation is related to consciousness and self-management that made by corben in 2009 (cerin, spirok, and orgreen, 2009) cerin et al reported stability questionnaire as alpha Cronbach for social-affectional learning have reported respectively organization of task (69\%), peers relations (80\%) self-regulation (80\%).

Validity of this questionnaire by five persons from experts of education and psychology was confirmed and sabzavari (1389) has extimated it's ending coefficient by alpha Cronbach for organization components of task (0.74) peers relations $(0.72)$ self-regulation $(0.76)$ and for whole questionnaire $(80 \%)$. In onother research by jamali pa ghale et al (2010) that was done on boys four and five primary in Esfahan city, data by analyzing confirmation factor was analyzed and Cronbach coefficient of whole and sub scales respectively 0.85 , self-regulation 0.71 , peers relations 0.83 , regulation of tasks 0.79 were calculated and confirms analyzing confirmation factor also in research of three structures (self-regulation, peers relations, regulation of tasks).

\section{Findings}

\subsection{Descriptive Statistics}

This part is allocated to description of research variables by using central indexes, dispersion indexes, and distribution indexes.

\subsection{Loneliness Sense}

Table 2. Mean, standard deviation of loneliness sense of groups in pretest and posttest $(n=40)$

\begin{tabular}{llllll}
\hline variable & time & \multicolumn{2}{c}{ Experiment $(\mathrm{n}=20)$} & \multicolumn{2}{l}{ Witness $(\mathrm{n}=20)$} \\
\cline { 3 - 6 } & & $\underline{\mathrm{M}}$ & $\underline{\mathrm{SD}}$ & $\underline{\mathrm{M}}$ & $\underline{\mathrm{SD}}$ \\
\hline loneliness & Pretest & 79.5 & 10 & 77.4 & 5.3 \\
& posttest & 70.05 & 5.3 & 75.45 & 7 \\
\hline
\end{tabular}


According to information of above table, loneliness sense of experiment group in posttest related to pretest is decreased. While these changes in witness group is very low.

\subsection{Social Affectional Learning}

Table 3. Mean and standard deviation of social affectional groups in pretest and posttest $(\mathrm{n}=40)$

\begin{tabular}{llllll}
\hline variable & time & \multicolumn{2}{l}{ Experiment $(\mathrm{n}=20)$} & \multicolumn{2}{l}{ Witness $(\mathrm{n}=20)$} \\
\cline { 3 - 6 } & & $\underline{\mathrm{M}}$ & $\underline{\mathrm{SD}}$ & $\underline{\mathrm{M}}$ & $\underline{\mathrm{SD}}$ \\
\hline loneliness & Pretest & 76.35 & 10 & 77.4 & 5.3 \\
& posttest & 70.05 & 5.3 & 75.45 & 7 \\
\hline
\end{tabular}

As above table shows, mean of social affectional learning of children who exposure in education of affectional connect skills (experiment group) is increased, while existence of numbers of pretest and posttest of witness group are almost same.

\section{Inferential Statistics}

First hypothesis: education of affectional connects skills effects on loneliness of children above 10 years of mothers in night shift in Saveh hospital.

The first hypothesis by covariance has tested, but before applying exam, hypotheses of using this test were checked.

\section{Checking homogeneity of regression}

Calculations related to checking this hypothesis showed that achieved $\mathrm{F}$ for covariate $\mathrm{x}$ group is not meaningful ( $\mathrm{p}=0.4, \mathrm{df}=1.36, \mathrm{~F}=0.78$ ), therefore hypothesis of homogeneity of regression coefficient in two groups of witness and experiment are accepted.

Checking the existence of linear relation between auxiliary and dependent random variable. For checking this hypothesis, covariate chart was used.

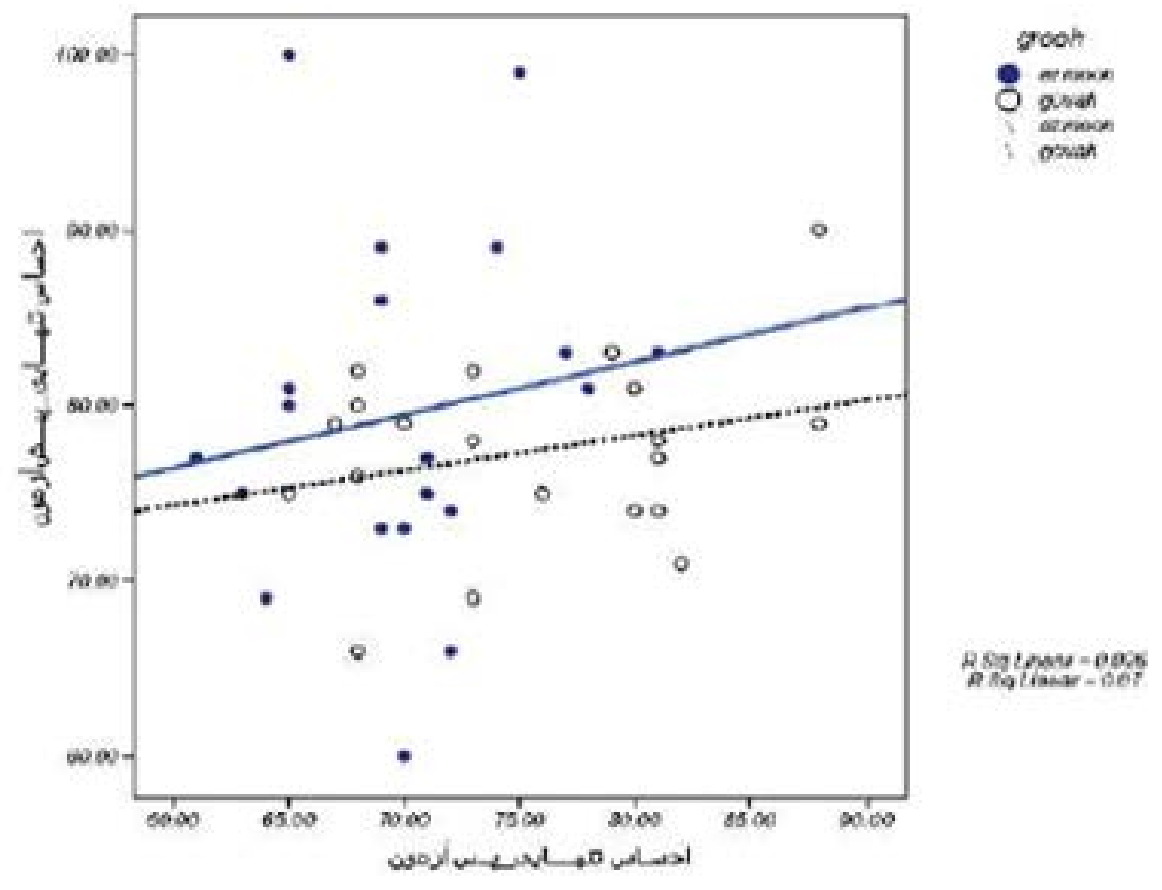




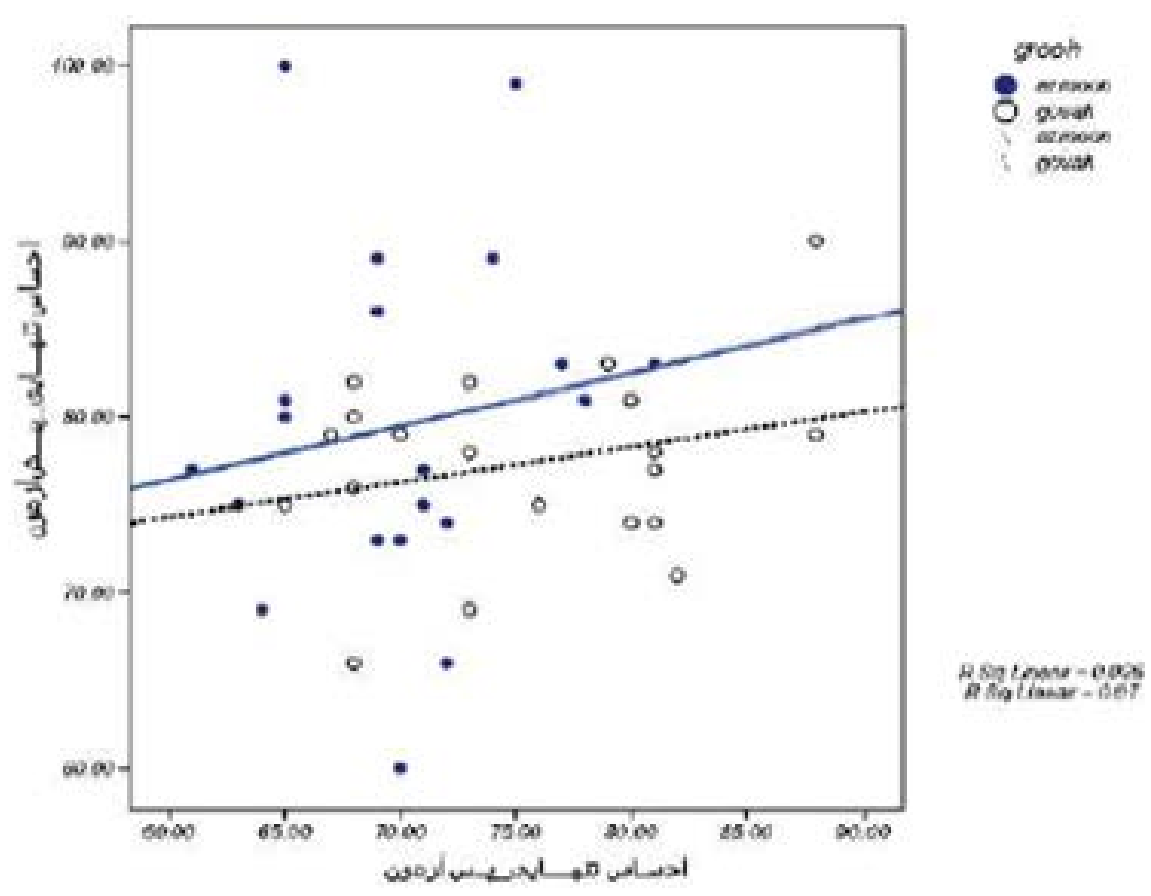

Figure 1. Covariate chart between auxiliary variable and dependent variable of experiment group and witness group in variable of loneliness sense

Due to nonexistence of intersection of regression lines, one can accepts linear relation of auxiliary random variable and dependent variable.

\section{Checking homogeneity of variances}

Table 4. summary of Loien test for checking homogeneity of variance of groups in speed of fast reading

\begin{tabular}{cccc}
\hline Statistics F & Freedom level 1 & Freedom level 2 & Level of meaningfulness \\
\hline 3.5 & 1 & 38 & 0.07 \\
\hline
\end{tabular}

The level of meaningfulness of Levin shows that homogeneity of variances of groups in loneliness sense has not impinged.

Table 5. Summary of Ancova test for checking the effect of education of affectional skills on loneliness sense

\begin{tabular}{cccccccc}
\hline $\begin{array}{c}\text { Source of } \\
\text { changes }\end{array}$ & $\begin{array}{c}\text { Sum of } \\
\text { squares }\end{array}$ & $\begin{array}{c}\text { Freedom } \\
\text { degree }\end{array}$ & $\begin{array}{c}\text { Mean of } \\
\text { squares }\end{array}$ & $\begin{array}{c}\mathrm{F} \\
\text { relation }\end{array}$ & $\begin{array}{c}\text { Level of } \\
\text { meaningful }\end{array}$ & $\begin{array}{c}\text { Volume of } \\
\text { work }\end{array}$ & $\begin{array}{c}\text { Power of } \\
\text { test }\end{array}$ \\
\hline Covariate & 50.6 & 1 & 50.6 & 1.31 & 0.3 & 0.034 & 1 \\
Group & 319.5 & 1 & 319.5 & 8.2 & 0.01 & 0.182 & 0.99 \\
Error & 1433.3 & 37 & 38.7 & & & & \\
whole & 213478 & 40 & & & & & \\
\hline
\end{tabular}

According to information of above table and by controlling work pretest, $\mathrm{F}$ test, in level 0.01 is meaningful $(\mathrm{P}=0.01, \mathrm{~F}(1.37)=8.2)$, in another words, between numbers of test of witness group and experiment, difference of meaningfulness exists. Table 1 shows that it has loneliness sense and by 99 percent of confidence it claimed that education of affectional connect skills makes decreasing loneliness sense of children above 10 years of mothers in night shift in Saveh hospital. Amount of work also shows that amount 18.2 percent of work of loneliness of tests by assignment to witness and experiment groups can be theorized. And while changing numbers in witness group is not sensible. Therefore has zero hypothesis.

\subsection{Second hypothesis}

Education of affectional connect skills on social affectional learning children above 10 years of mothers in night 
shift in Saveh hospital is effective.

Second hypothesis also by using covariance statistical model was tested; but using this test requires setting 5-5.2 5.2 Below Hypotheses

\section{Checking homogeneity of regression}

The lebel of meaningfulness of $E$ test does not meaningful in covariate $\times$ meaningful group.

It can be said that data is set from hypothesis of regression coefficients in variable of social affectional learning.

The checking existence of linear relation between auxiliary and dependent random variable

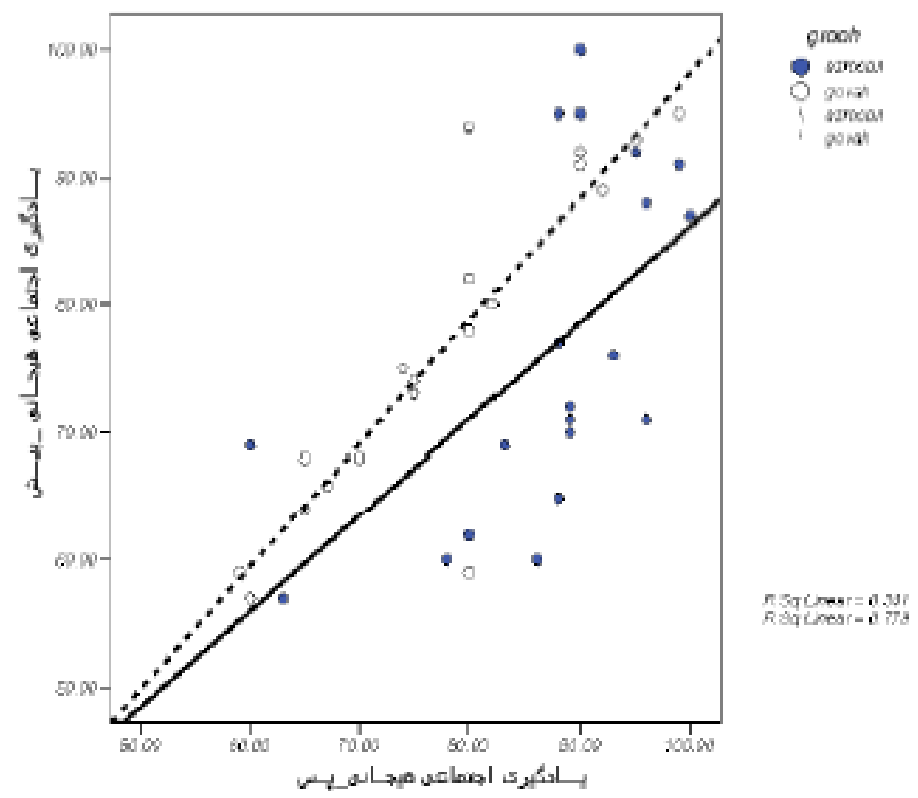

Figure 2. The reaction between auxiliary and dependent variable of experiment group in case of social affectional learning variable

As covariate chart shows, regression almost is parallel, that is, there is linear relation between variables of two groups.

\section{Checking homogeneity of variances}

Table 6. Summary of loien test for checking homogeneity of variances of groups in social affectional learning variable

\begin{tabular}{llll}
\hline F statistics & Freedom degree 1 & Freedom degree 2 & Level of meaningfulness \\
\hline 1.8 & 1 & 38 & 0.2
\end{tabular}

According to above table information, F loien test is not meaningful; that is, covariate dependent variable in groups is same.

Table 7. Summary of Ancova for checking the effect of education of affectional skills on social affectional learning

\begin{tabular}{lllllllll}
\hline $\begin{array}{l}\text { Source } \\
\text { changes }\end{array}$ & of & $\begin{array}{l}\text { Sum of } \\
\text { squares }\end{array}$ & $\begin{array}{l}\text { Freedom } \\
\text { degree }\end{array}$ & $\begin{array}{l}\text { Mean of } \\
\text { squares }\end{array}$ & $\begin{array}{l}\text { F } \\
\text { relation }\end{array}$ & $\begin{array}{l}\text { Level } \\
\text { meaningfulness }\end{array}$ & $\begin{array}{l}\text { Volume of } \\
\text { work }\end{array}$ & $\begin{array}{l}\text { Power } \\
\text { of test }\end{array}$ \\
\hline Covariate & 2520.6 & 1 & 2520.6 & 43.6 & 0.01 & 0.541 & 1 \\
Group & 926.5 & 1 & 926.5 & 16.04 & 0.01 & 0.302 & 0.97 \\
$\begin{array}{l}\text { Error } \\
\text { whole }\end{array}$ & 2137.1 & 37 & 57.8 & & & & \\
\hline
\end{tabular}

The results of above table suggests that by controlling the effect of pretest, level of meaningfulness of $\mathrm{F}$ group, is less of $0.05(\mathrm{P}=0.01, \mathrm{~F}(1.37)=16.04)$. 
In another words, between test of groups of experiment and witness, in terms of social affectional learning, there is a meaningful difference, the comparison of mean of groups in table 2-4 shows that social affectional learning of children of experiment group that exposure in education of affectional connect skills, are meaningfully increased, while such change in witness group is not observed. Therefore, one can concludes by $99 \%$ that education of affection connect skills leads to increase of social affectional learning of children above 10 years of mothers in night shift in Saveh hospital. So almost 30.2 percents of this increase, is related to education of affection connect skills.

\section{Debate and Conclusion}

Education of affectional connects skills causes decreasing loneliness sense of children above 10 years in night shift in Saveh hospital.

- It can be said that this research in term of loneliness sense of children alignment with Zimbard andradel (2001).

The researches related to loneliness sense in last years shows significant growth that its reasons can be considered as increasing development of this phenomenon in communities, interest of researchers in checking human relations, and preparation of related psyche-meter scales.

- It can be said in theorizing this hypothesis

Children in family and society by communication pattern, transit own sensations and affections. Due to that family is first society that child is in there, and child's personality informed in it, so the role of parents, and particularly mother being raised in there. Therefore affectional connect causes improving communication patterns, showing sensations in safe place and decreasing loneliness sense in children.

Second hypothesis:Education of affectional connects skills is effective on social-affectional learning of children above 10 years of mothers in night shift in Saveh city hospitals.

This research is alignment with researches by Stateton and Reed (2003), Zimbard and radel (2001), paghalejamali et al. (2013), Sadri, Akbarizadeh and Ponsheh (2008), Khosravi and Sabahi and Nazeri (2014).

Intimacy and the way of affectional responding of mother can be a good prediction for self-concept and self-confident of children. Web sStrateton and Reed (2003) over researches, conclude that education of empathy skills, communicational skills, and friendships, management of rage and education of solving personal problems, learning and observing school rules can be effective in preventing anger and aggression and finally school dropout of teenagers. Parent's kindness can be effective on existence of positive relation between mother and child in child's success, because based on this kindness, the child accepts and increases expectations and demands of parents, and causes that child risks and searches.

Timidity basically adventitious and learned behavior and for resolve it, it must be de-learned and new suitable behavior sweep up in person. In researches done by Zimbardo and Radel (2001), relationship with timidity, it concluded that education of social skills can be very effective in eliminating or decreasing timidity and social withdrawal.

Paghalejamali et al. (2013) research shows that educations insist on social and affectional skills such as consciousness, group work, and sympathy for self and others. Through these programs, the persons learn that know their affections and apply their cognitive and interpersonal skills by suitable way.

Sadri, Akbarzadeh and Poushneh (2008) shows that education of social affectional skills is effective in increase main components of emotional intelligence of students. Khosravi, Sabahi and Nazeri research (2014) shows that education of life skills has been effective on improving non-verbal connect ability and devoiced women communicational skill.

The results of present research suggests that education of affectional connect skills is effective on social affectional learning of persons and causes progress of persons in management of mental pressure skills, solving problem and decision, solving antagonisms, autonomy, leadership,loyalty and growth of suitable behaviors (Zins et al, 2001).

One of the consequences of default in social skills is loneliness sense. Loneliness sense only means the difference between suitable level and available level in persons social relations and more this difference, more loneliness (Naderi and Haghshenas, 2009).

Finally it can be concluded that this research in respect of other researches. Affectional connect skills is effective in decrease of loneliness sense and increase social affectional learning. 


\section{References}

Bandura, A. (2001). Social cognitive theory: An agentic perspective. Annu Rev Psychol, 52, 1-26. https://doi.org/10.1146/annurev.psych.52.1.1

Bothma, J., Franciska, L., \& Monteoy, D. K. (2004). Selfregulated learning as a prerequisite for successful distance learning, 24(2), 141-197.

Collaborative for Academic, Social and Emotional Learning(CASEL). (2008). Connecting Social and Emotional Learning withMental Health. Retrieved 7July 2007 from. http://www. promoteprevent.org

Hamidi, M., \& Berandak, M. (2007). Education of skill in terms of affectional/social in respect of improvement and cognitive functions, design and experiment of one educational period for increase affectional intelligence, education, 23(4), 29-52.

Jamalipaghale, S., Abedi, A., Aghaye, E., \& Zare, R. (2010). Comprehensive super-analyzing relation between affectional intelligence with mental health. Research Magazine in Psychology Health, 4(3), 21-31.

Khosravi, M., Sabahi, P., \& Nazeri, A. (2011). Checking effectiveness if education of communicational skills in decreasing loneliness sense and depression of devoiced women under foundation relief of Shahroud city. Monthly scientific research magazine of Shahrouduniversity, 21(112).

Naderi, F., \& Haghshenas, F. (2009). Relation between impulsiveness and loneliness sense by using of mobile in students of Azad university Ahvaz unit: 112-113.

Salovey, P., Mayer, J. D. \& Caruso, D. R. (2002). The positive psychology of emotional intelligence,for inclusion in C. R, Snyder \& S. J, Lopez, The Handbook of positive psychology UniversityPress. New York oxford: 159-171.

Shahini, N., Asayesh, H., Ghobadi, M., \& Sadeghi, J., (2012). Checking correlation social support, loneliness sense and pleasant from life among students of medical sciences Golestan in 2010. Researcher (research magazine of medical sciences of SahidBeheshtiuniversity), 17th year, (6), 302-306

Webster-Stratton, C., \& Reid, M. J. (2003). Treating Conduct Problems andStrengthening Social and EmotionalCompetence in Young Children: The DinaDinosaur Treatment Program. Journal of Emotional and Behavioral Disorders, 11(3), 130-143. https://doi.org/10.1177/10634266030110030101

Zimbardo, P. G., \& Radle, S. L. (2001). The Shy child: A Parent>s Guide to preventing and Overcoming Shyness from Infancy to Adulthood. New York.

Zins, J. E., \& Elias, M., J. (2006). Social and Emotional learning. ING. Bear\& K. Mink (Eds), childeran needs III: development, prevention, and intervention. Bethesda, MD: National Association of School Psychologists.

\section{Copyrights}

Copyright for this article is retained by the author(s), with first publication rights granted to the journal.

This is an open-access article distributed under the terms and conditions of the Creative Commons Attribution license (http://creativecommons.org/licenses/by/4.0/). 